\title{
REFLEXÕES SOBRE O CARÁTER NORMATIVO DO DIREITO INTERNACIONAL E SOBRE O PAPEL DA SOBERANIA
}

\author{
LEONARDO NEMER CALDEIRA BRANT ${ }^{1}$ \\ BRUNO WANDERLEY JÚNIOR ${ }^{2}$
}

RESUMO: O direito internacional é uma ordem normativa sistematizada, apesar de persistirem críticas a tal constatação. Entre tais críticas está aquela que pressupõe que apenas um sistema normativo tal como as ordens jurídicas internas poderia caracterizar um sistema normativo válido, o que não é correto visto que a ordem internacional não precisa refletir a mesma estrutura da ordem interna para se configurar como um sistema normativo válido. Outro argumento levantado se refere à inexistência de um sistema coercitivo efetivo na ordem internacional, mas tal constatação se mostra falaciosa visto que a aplicação de sanção coercitiva não é requisito para a existência de normas ou de sistemas normativos, mas sim de sua eficácia. Mas se o direito internacional é uma ordem normativa, o que o difere de outros ramos do direito? Por meio da análise do pensamento de autores de diferentes escolas positivistas, o presente artigo propõe demonstrar que a soberania é o principal elemento que diferencia o direito internacional de outros ramos do direito. Para tal fim, as críticas relativas à normatividade do direito internacional serão refutadas, e será demonstrada que a soberania está na gênese do direito internacional, o legitimando e atribuindo-lhe particularidades.

PAlavras-Chave: Direito Internacional; Ordem Normativa Sistematizada; Soberania; Igualdade entre os Estados.

${ }^{1}$ Doutor em Direito Internacional pela Université Paris X - Nanterre. Professor Associado de Direito Internacional Público da UFMG e Professor Adjunto da PUC Minas. E-mail: leonardo@cedin.com.br.

2 Doutor em Direito pela UFMG. Professor Associado da Faculdade de Direito da UFMG. 


\title{
REFLECTIONS ON THE NORMATIVE CHARACTER OF THE INTERNATIONAL LAW AND THE SOVEREIGNTY'S ROLE
}

\begin{abstract}
International law is a systematized normative order, although criticism of this reality persists. Among these criticisms is that which presupposes that only a normative system such as the domestic legal orders could characterize a valid normative system, which is not correct since the international order does not need to reflect the same structure of the internal order to be configured as a system normative. Another argument raised is that there is no effective coercive system in the international order, however this finding is flawed since the application of coercive sanctions is not a requirement for norms or normative systems, but for their effectiveness. But if international law is a normative order, what is its difference in relation to other branches of law? Through the analysis of the work of authors of different positivist schools, this article proposes to demonstrate that sovereignty is the main element that differentiates international law from other branches of law. To this end, criticisms regarding the normativity of international law will be refuted, and it will be demonstrated that sovereignty is in the genesis of international law, legitimizing and attributing particularities to it.
\end{abstract}

KEYWORDS: International Law; Systematized Normative Order; Sovereighty; Equality etween States. 


\section{REVISTA ESTUDOS INSTITUCIONAIS}

\section{INTRODUÇÃO}

O direito é um modo de controle social, mas ele não é certamente o único conjunto normativo capaz de regulamentar um determinado comportamento. As normas morais e éticas, por exemplo, gênero do qual o direito é apenas uma espécie, prescrevem atitudes desejáveis e podem ser igualmente de natureza política, profissional, familiar, religiosa, ou mesmo de cunho social. $\mathrm{O}$ direito internacional, como qualquer ordem normativa, possui, contudo, especificidades que lhe são particulares e que o distingue dos outros modos de controle social. Mas afinal, como reconhecê-lo? Sua característica essencial reside no fato de que ele não apenas molda, mas normatiza uma determinada relação social.

Ademais, o direito internacional não é uma obrigação jurídica isolada. Afinal, um conjunto de normas pode não ser uma ordem jurídica, assim como um conjunto de folhas e galhos pode não ser necessariamente uma árvore (VIRALLY, 1969, p. 201-203). O direito internacional com as devidas qualidades que lhe são particulares está atrelado a uma ordem jurídica que lhe confere um sentido e um alcance determinado. A norma internacional não é, portanto, uma obrigação de comprovada natureza vinculante, mas destacada do conjunto. Ao contrário, esta deve ser vista como um agrupamento ordenado e uniforme. Ela é uma peça na formação de uma unidade lógica e coesa (VIRALLY, 1975, p. 453-467). Em outras palavras, o direito internacional é um sistema normativo, ou seja, um conjunto de regras agrupadas de forma sistemática, coerente e com certa identidade e integração.

A natureza jurídico-normativa das obrigações que dele decorre, assim como a sua lógica coesa, uniforme e sistematizada representam características que orientam sua concepção. O direito implica, portanto, em obrigações que são formuladas e percebidas como jurídicas e, deste modo, dotadas de força normativa (DUPUY, 2006, p. 12).

Tal característica remete necessariamente a uma afirmação complementar. Além de normativo, o direito internacional é forçosamente constituído por propriedades peculiares, decorrentes de uma ordem sistêmica organizada e coerente, e não apenas de uma justaposição lacunar de regras mal articuladas entre si (COMBACAU, 1986, p. 85-105).

Por consequência, a natureza normativa, vinculante e sistematizada do direito internacional pode ser demonstrada a partir do conceito de soberania, que interage na ordem internacional moldando-a e adaptandoa aos seus imperativos. A soberania é, portanto, o elemento central na constituição das especificidades de uma ordem jurídica vinculante e sistematizada. 
O direito internacional é uma ordem normativa pelo simples fato de ser tratado como tal pelos seus autores e destinatários. Não há prova mais irrefutável. Suas especificidades não o desqualificam como obrigação normativa (DUPUY, 2006, p. 24). Ao contrário, elas permitem uma adaptação à realidade do universo social no qual ele se insere, garantindo-lhe não apenas eficácia, mas, igualmente, legitimidade. ${ }^{3}$ Contudo, apesar desta constatação evidente, alguns argumentos contrários à força normativa do direito internacional vêm sendo suscitados. ${ }^{4}$ Cabe, portanto, peremptoriamente refutá-los, o que será feito na Seção II.

Além de refutar os argumentos contrários à normatividade do direito internacional, entretanto, deve-se analisar qual o elemento que o diferencia de outros ramos do direito, e consequentemente gera estranhamento. Tal tarefa será reservada à Seção III.

\section{A REJEIÇÃo À NATUREZA NORMATIVA DO DIREITO INTERNACIONAL}

O direito internacional goza de especificidades que lhe são próprias, mas que em nada reduzem o seu grau de autoridade jurídica. São, portanto, inexatos os argumentos que negam a autoridade de sua ordem normativa, fundados tanto em uma suposta natureza arcaica e primitiva do direito internacional quanto nas particularidades de sua estrutura sancionatória e coercitiva (BRANT, 2013, p. 367-375).

\section{A natureza arcaica e primitiva do direito internacional como fundamento de negação da sua autoridade normativa}

Parte minoritária da doutrina tem sustentado que uma norma só pode existir se nela estiverem presentes os elementos que conhecemos no ordenamento jurídico interno. Nesse sentido, a refutação da autoridade normativa do direito internacional assenta-se na premissa segundo a qual a validade de uma norma dependeria da existência de uma sociedade

\footnotetext{
${ }^{3}$ Aust (2005, p. 04) elucida nesse sentido que a força normativa e vinculante do Direito Internacional não advém da existência de uma polícia, de cortes ou prisões, mas, ao contrário, está respaldada no consentimento dos Estados, seja ele explícito ou tácito, de se vincular às normas que compõem esse sistema.

${ }^{4}$ Dentre os juristas defensores de uma posição negativista, cita-se Espinosa, J. Binder, A. Lasson, J. Bolton, A. Lundstedt, M. Merle, F. Somlo, Gumplowicz, e Binder, Cf. Pereira (2006, p. 26-27).
} 


\section{REVISTA ESTUDOS INSTITUCIONAIS}

JULHO/DEZEMBRO - ISSN 2447-5467

institucionalizada dotada de uma estrutura e de uma organização jurídica distinta e superior aos destinatários da norma (O'BRIEN, 2001, p. 03). Por conseguinte, uma ordem normativa seria dependente de uma superestrutura social verticalizada composta por poderes legislativo, executivo e jurisdicional adaptados obrigatoriamente ao modelo reservado ao sistema doméstico e ao direito interno.

Assim, embora hoje se possa reconhecer a ideia da existência de uma comunidade internacional constituída em torno de interesses comuns aos Estados, sustenta-se, neste caso, que esta não seria a representação legal de uma ordem jurídica internacional. $\mathrm{O}$ argumento central procura opor a sociedade interna organizada e disciplinada juridicamente, a sociedade internacional de natureza anárquica e refratária a uma eventual noção moderna do direito (KOLB, 2013, p. 06). Tal posicionamento tem origem nas ideias originais de Hobbes e Espinosa "que assimilam a sociedade internacional a uma sociedade natural e as relações entre Estados soberanos a relações de força" (PELLET; DAILLIER, 2009, p. 88). ${ }^{5}$

Os defensores desta posição pretendem demonstrar que a esfera internacional convive com um mundo ainda dividido em soberanias fragmentadas, na qual inexiste a figura de um Estado mundial ou de um legislador global que agiria unilateralmente em nome de uma pretensa ordem pública global e cujas decisões teriam efeito erga omnes (BROWNLIE, 1995, p. 33). Nesta atmosfera o direito internacional seria basicamente um direito em gestação, profundamente atrasado no processo de evolução normativa. ${ }^{6}$ Visto como moralidade positivada, o direito internacional apresentaria lacunas intransponíveis e poderia apenas ser concebido como uma ordem normativa a partir de seu desenvolvimento e de sua aproximação da lógica que orienta o direito interno.

Hoje, tais argumentos não fazem o menor sentido. Com efeito, é da relação social entre os membros de uma determinada sociedade que surge o direito como instrumento de orientação de conduta. Em outras

\footnotetext{
${ }^{5}$ Ademais, observa-se que esse posicionamento também foi esposado por John Austin, jurista Inglês fundador da escola analítica de jurisprudência. $\mathrm{O}$ jurista defendia, conforme verifica-se a partir da leitura de sua obra "A Província da Jurisprudência Determinada", publicada em 1831, que a ausência de uma autoridade superior aos Estados incumbida de fazer cumprir as normas internacionais descaracterizaria o Direito Internacional como sistema jurídico-normativo (O'BRIEN, 2001, p. 29).

${ }^{6}$ Quanto a esse ponto, Bedjaoui (1991, p. 03) admite que o Direito Internacional "tem um atraso a recuperar em comparação com o direito interno, em geral muito mais desenvolvido". Importante apontar, no entanto, que o autor reconhece o Direito Internacional como um ramo "em desenvolvimento, em razão de sua extensão a novos espaços, de seu enriquecimento por novos sujeitos, do progresso de sua codificação e das rápidas transformações da sociedade internacional".
} 


\section{REFLEXÕES SOBRE O CARÁTER NORMATIVO DO DIREITO INTERNACIONAL E SOBRE O PAPEL DA SOBERANIA}

palavras, uma norma jurídica, para gerar obrigações, não é dependente de uma superestrutura institucionalizada. Não há que se falar, portanto, em um dogmatismo de uma via única no desenvolvimento de uma ordem normativa. $\mathrm{O}$ direito não existe unicamente quando preenche os requisitos impostos pelo universo jurídico interno, pois não são as características do direito constitucional que estabelecem os elementos essenciais da qualificação de ordem normativa. $\mathrm{O}$ direito não decorre de um modo de produção específico e não existe unicamente porque responde aos imperativos das sociedades nacionais. Ele pode ser originado de formas variadas e sua existência é dependente do reconhecimento de sua aplicação por um determinado grupo social, de modo a se adaptar a uma determinada lógica social.

A realidade é que o direito interno e a ordem normativa internacional podem coexistir dentro de estruturas que lhes são próprias e que respeitam a diversidade de suas especificidades. Dito de outro modo, o direito doméstico das sociedades estatais e o direito da sociedade internacional não devem imperiosamente ter origem no mesmo molde e seguir propriamente o mesmo rito (BROTÓNS, 2007, p. 46). Não há que se negar, portanto, a existência do direito internacional ou considerá-lo como primitivo ou arcaico unicamente por este não responder aos mesmos fundamentos que regem o direito constitucional e doméstico. Em verdade, tem-se que o direito internacional é apenas uma ordem normativa diferente, governada por uma lógica distinta e destinada a um grupo social com especificidades que lhe são particulares. A força normativa do direito internacional está, portanto, impressa na sua própria construção, no seu desenvolvimento particular e na aceitação de sua natureza normativa pelos autores e pelos destinatários (BRANT, 2013, p. 367-375).

\section{O modelo da sanção na esfera internacional como argumento de negação do direito internacional}

O segundo argumento daqueles que negam a autoridade normativa do direito internacional revela-se de forma mais complexa. Seus defensores sustentam que a natureza anárquica da sociedade internacional, somada ao constante conflito de soberanias desejosas de impor, por qualquer modo cabível, conveniente ou possível os seus interesses soberanos, são incompatíveis com a ideia de existência de uma ordem normativa.

No centro de todo o debate estaria a hipotética ausência, na esfera internacional, de um poder coercitivo centralizado e com o devido 


\section{REVISTA ESTUDOS INSTITUCIONAIS}

monopólio do uso da força, capaz de sancionar qualquer eventual violação normativa (CAMPOS, 1998, p. 64-66). Afinal, como justificar a validade do direito internacional diante da falta de um poder de polícia universal gozando do monopólio do uso da força, ou seja, com poderes análogos àqueles concedidos ao Estado no plano doméstico? Como reconhecer a existência do direito internacional face ao tradicional regime de forças que move as relações internacionais? Em outras palavras, se as relações internacionais refletem única e exclusivamente uma lógica de poder puro, sem nenhum tipo de controle coercitivo, como admitir que tal sistema esteja submetido a uma ordem jurídica?

Esta é o principal argumento que conduziu Kelsen (1962, p. 46-55) e Guggenheim (1967, p. 02), a definirem a existência de uma ordem jurídica a partir da aplicação de um modelo dotado de instrumentos e mecanismos de coerção. ${ }^{7}$ Para estes autores, as normas jurídicas se diferenciam das simples regras de conduta, de cortesia, de prudência, de obrigações morais ou de todas as outras normas sociais, em razão de sua força obrigatória e por serem dotadas de uma sanção socialmente organizada e suscetível de ser aplicada pela força (PELLET; DAILLIER, 2009, p. 103-104).

Este posicionamento refletiu-se igualmente na jurisprudência. No caso Fischbach e Friedericy de 1903 da Comissão Mista de Reclamações Alemanha-Venezuela, o juízo arbitral declarou que o direito internacional não é direito no "sentido em que é usualmente definido. Não é uma norma de conduta prescrita por um poder soberano. Ele resta, portanto, assentado em um acordo. A obediência a ele é somente voluntária" (BISHOP, 1965, p. 168; BUERGENTHAL; MURPHY, 2003, p. 11).

Embora acolhido pela doutrina e demonstrado em situações excepcionais pela jurisprudência, tal argumento diverge hoje do senso comum acolhido na esfera internacional (REALE, 2004, p. 50-53). Duas são as razões: a primeira é que a sanção coercitiva é um atributo que se vincula à eficácia da norma, e não à sua existência. A segunda se refere ao fato de que certas normas não admitem recurso coercitivo, visto que não necessitam de ação para que sejam executadas.

Hanna Arendt definiu o conceito de autoridade como a capacidade de se obter obediência sem que seja preciso o recurso à força coercitiva. Em outras palavras, se o uso da força é necessário para o cumprimento de uma ordem é porque a autoridade propriamente dita não existe (ARENDT, 1992, p. 129).

\footnotetext{
7 Para H. Kelsen, a sanção representa um elemento constitutivo da noção de norma jurídica (ABI-SAAB, 1987, p. 117).
} 


\section{REFLEXÕES SOBRE O CARÁTER NORMATIVO DO DIREITO INTERNACIONAL E SOBRE O PAPEL DA SOBERANIA}

O conceito proposto revela-se interessante uma vez que permite desvincular a necessidade da coerção para a garantia da autoridade oriunda da validade da norma. Nessa perspectiva, se a autoridade existe é porque a obrigação está presente, e o uso da força é consequentemente dispensável. A ordem normativa, portanto, subsiste porque nela se reconhece a autoridade, e não porque o destinatário da ordem teme a coerção que poderá impô-la. Neste sentido, a validade da norma não tem relação direta com o poder coativo (ALLOT, 1999, p. 31-50). O direito afirma-se, assim, como uma ordem cuja autoridade não é exterior a ele. $\mathrm{O}$ poder coercitivo age simplesmente no aumento do custo da violação de uma norma já existente e válida. Ele é um princípio de eficácia, e não de validade.

Consequentemente não se pode estabelecer relação de condicionalidade ou causalidade entre o cumprimento da norma e seu fundamento de validade (SCOBBIE; EVANS, 2003, p. 59-87). Existência e eficácia são duas dimensões distintas. Enquanto a primeira é o resultado da formação da norma, a segunda age na transformação da norma em realidade social e política (PELLET, 1992, p. 22-53). Confundi-las seria incorrer na contradição de exigir a existência de um elemento coercitivo exterior à norma como seu fundamento e limitar o direito a mera força sancionatória (ONU, 1945). Tal erro levaria indelevelmente ao colapso do sistema normativo e à sua consequente autonegação (SHAW, 2003, p. 05).

Tal entendimento pode ser ilustrado por um exemplo trivial. Imaginemos que voltando de uma festa tarde da noite, Bernardo, em uma avenida pouco movimentada, se confronta com um sinal de trânsito vermelho. A ordem normativa é clara. $\mathrm{O}$ condutor deve evidentemente parar o veículo (a norma existe). Contudo, o motorista pode executar ou não a obrigação normativa. Essa é uma opção própria ao destinatário da norma, que não provêm da norma em si, mas da avaliação do custo e benefício entre o respeito da boa-fé e a violação normativa. $O$ fato é que avançar o sinal ou respeitá-lo é uma decisão que deverá ser tomada por Bernardo, de forma que em nenhum dos dois casos, a norma deixará de ser vinculante ou o destinatário deixará de reconhecê-la como tal e de estar a ela submetido. Portanto, se Bernardo permanecer parado ou, se por razões de urgência, negligência ou imprudência, decidir ultrapassar o sinal vermelho, sua atitude é fruto de sua própria avaliação, conveniência e senso de responsabilidade. A força vinculante e a existência da norma indicando "pare" é indiferente a esta avaliação do condutor.

Imagine, em seguida, que neste caso seja incluído ao lado do sinal de trânsito um radar, cuja finalidade seria a de verificar a falta, comprová-la 


\section{REVISTA ESTUDOS INSTITUCIONAIS}

JULHO/DEZEMBRO - ISSN 2447-5467

e impor uma sanção sob a forma de multa. Obviamente que, a depender do valor da multa, tal dispositivo sancionatório poderia agir de forma a modificar o comportamento de Bernardo. Nesse sentido, uma multa no valor de $\mathrm{R} \$ 5$ e uma multa no valor de $\mathrm{R} \$ 5.000$ poderiam afetar de formas distintas a avaliação do destinatário da norma. Isso significa que, a força da norma para o destinatário pode ser variável dependendo da qualidade da sanção, mas não significa que a norma existe ou deixa de existir em virtude da sanção. A sanção coercitiva não delega validade à norma "pare", oriunda do sinal vermelho, mas poderá simplesmente conduzir o destinatário, neste caso o condutor Bernardo, a um determinado comportamento decorrente de sua avaliação do custo e do benefício relacionados ao cumprimento ou descumprimento da obrigação normativa. Validade e eficácia não se confundem. Observa-se, assim, que a sanção coercitiva age como instrumento de eficácia normativa, ao invés de atuar como mecanismo de reconhecimento de validade da norma. Em outras palavras, após a produção legal da norma, seu alcance não se mostra dependente da realização da conduta prevista no mundo dos fatos, nem da eventual sanção originada de sua violação.

Tal hipótese pode ser naturalmente transferida para a ordem internacional. Ou seja, uma eventual ação contrária a uma ordem normativa, proveniente de um determinado sujeito de direito internacional não compromete a existência da obrigação normativa (CANAL-FORGUES; RAMBAUD, 2011, p. 20). Evidentemente, um sistema coercitivo, imparcial e eficiente pode pesar a balança em prol de comportamentos favoráveis ao cumprimento da norma, mas este não é um elemento distintivo da norma em si (SCHACHTER, 1960, p. 54; GOODRICH; HAMBRO, 1969, p. 263; ROSENNE, 1997, p. 245; REISMAN, 1971; KERLEY1976, p. 283). O direito, qualquer que seja sua natureza, não deixa de existir em razão dos fundamentos que orientam a sua estrutura coercitiva. Na verdade, a efetividade da norma não constitui uma condição da sua juridicidade (DE BÉCHILLON, 1997, p. 61).

Do mesmo modo, admitir a possibilidade de violação do direito não conduz à conclusão de sua inexistência (WECKEL, 1996, p. 437). O próprio direito interno segue a mesma lógica, na medida em que ele também não é capaz de prevenir definitivamente o uso da violência em seus domínios, embora sua natureza normativa seja incontestável (KRATOCHWIL, 2010, p. 86-87). Assim como os Estados podem decidir por um comportamento ilegal ao violar uma obrigação normativa, qualquer membro de uma sociedade interna também pode fazê-lo, e sofrer as devidas consequências, sem que isto signifique a negação da norma. Portanto, o descumprimento do direito interno ou internacional 


\section{REFLEXÕES SOBRE O CARÁTER NORMATIVO DO DIREITO INTERNACIONAL E SOBRE O PAPEL DA SOBERANIA}

não representa sua inexistência. ${ }^{8}$ Ao contrário, a responsabilidade decorrente, seja por violação interna ou internacional, prova sua autoridade e aplicabilidade. A eficácia das medidas coercitivas face ao ilícito constitui um problema distinto que deriva não da existência da norma, mas da sua efetividade. Em outros termos, "os delitos não anulam o direito, eles o afirmam" (STRUPP, 1934, p. 207).

Conclui-se, assim, que a qualidade jurídica e normativa do direito internacional é atribuída de acordo com a natureza material (conteúdo) e formal (processo de elaboração) da norma, e não em razão dos elementos de coerção e sanção a ela vinculados. Segue-se a esse raciocínio que a existência e validade da ordem jurídica internacional, mesmo que estruturada em uma sociedade ainda nitidamente anárquica e descentralizada, independe da lógica sancionatória. ${ }^{9}$ Deste modo, não parece razoável aceitar que a habitual crítica relativa à incapacidade do ordenamento jurídico internacional de evitar efetivamente o uso da força nas relações internacionais, constitua um elemento que negue sua existência.

A necessidade de se diferenciar eficácia e existência tem ainda outras origens. Ao se analisar a tipologia e a função das obrigações jurídicas, o que se percebe é que certas normas simplesmente não admitem sanções, visto que sua execução prescinde de uma ação (FINNEMORE, 2000, p. 699-705). Tal fato pode ser observado na distinção entre normas regulatórias e normas constitutivas. Com efeito, o primeiro modelo normativo pode ser definido como obrigações que constrangem comportamentos e prescrevem ações. Seu objetivo fundamental é o de disciplinar a forma ideal de ação em face de uma prática regular dentro

\footnotetext{
${ }^{8}$ Buergenthal (2003, p. 09) faz importante ressalva nesse sentido, advertindo que "as violações dramáticas do Direito Internacional, principalmente aquelas envolvendo a ameaça ou uso da força, as quais atraem a atenção mundial, não deveriam nos cegar para o fato de um vasto corpo do Direito Internacional que regula o comércio internacional, as comunicações, o transporte, e as relações diplomáticas e consulares, é aplicado e respeitado tão rotineiramente quanto o direito nacional. Acrescenta ainda Dupuy (2006, p. 14) que "em comparação com o volume do conjunto e com o crescimento das relações jurídicas internacionais, os casos de violação do Direito Internacional, são relativamente pouco numerosos" e que "a maioria das normas de origem consuetudinária são respeitadas em sua maioria".

${ }^{9}$ Ao contestar o argumento sobre a negação da normatividade do Direito Internacional com fundamento na ausência de sanções sociais organizadas, Ruzié (2008, p. 04) admite que "a proibição do recurso à força e a eficácia limitada do poder de sanção das organizações internacionais contribuem ao enfraquecimento da eficácia do direito internacional". Contudo, o autor ressalta que, assim como na ordem internacional, "o direito interno comporta igualmente normas não sancionáveis".
} 


\section{REVISTA ESTUDOS INSTITUCIONAIS}

de um determinado grupo social. Têm-se como exemplo de normas regulatórias aquelas que impõem aos Estados condutas relacionadas à delimitação do espaço marítimo, ao tratamento de estrangeiros em seu território ou à utilização do espaço extra-atmosférico.

De forma distinta, as normas constitutivas estabelecem procedimentos, criam novos atores e definem interesses ou categorias de ação (DUPUY, 2006, p. 13). Essas têm como função a própria definição e caracterização de um determinado conjunto de práticas. As normas que orientam o jogo de xadrez são um bom exemplo. Seu objetivo é o de definir que tipo de prática pode ser realizada dentro do jogo, a sua dinâmica e o seu funcionamento. Observa-se que tais normas não foram elaboradas com a finalidade de evitar uma colisão de pedaços de madeiras movidos por pessoas em um tabuleiro. Esse tipo de prática (movimentação de peças em um tabuleiro) somente existe em função da criação das normas que definem o que é o xadrez (RUGGIE, 1998, p. 2225). Diante de tais normas, nestes, casos, não pode haver elementos sancionatórios.

No âmbito do direito internacional, pode-se mencionar como exemplos de normas constitutivas aquelas normas convencionais e consuetudinárias concernentes ao direito dos tratados, que estabelecem as condições de validade, entrada em vigor e término de convenções e outros instrumentos internacionais (DUPUY, 2006, p. 13). Nestes casos, em virtude da própria natureza da norma, qualquer modelo de sanção seria inútil visto que sua lógica normativa não é de causalidade. A eficácia e a observância destas normas são essenciais para a própria ação do sujeito, que toma a decisão com base em uma concepção pré-constituída, mas prescindem de mecanismo sancionatório. ${ }^{10}$

Tal distinção tem sido reconhecida mesmo que de forma indireta. $\mathrm{Na}$ esfera jurisdicional, verifica-se, com efeito, em um número expressivo de casos, que a execução de uma sentença internacional pode se dar apesar da ausência de qualquer comportamento subsequente. Este é o caso, por exemplo, das decisões puramente declaratórias que constatam que a conduta de um Estado foi conforme ou contrária ao direito internacional. Nestas situações não há realmente o que sancionar porque não há o que implementar. Assim, no caso do Estreito de Corfu, a Corte Internacional de

$10 \mathrm{O}$ mesmo argumento se aplica para a distinção feita por Hart (1994), entre normas primárias e normas secundárias. As primeiras seriam caracterizadas por prescrever comandos diretos de conduta aos sujeitos. Normas secundárias, por sua vez, teriam como objetivo principal o estabelecimento de procedimentos pelos quais as primárias poderiam ser identificadas, modificadas e promulgadas - regras de reconhecimento (recognition), de mudança (change) e de julgamento (adjudication), respectivamente. 


\section{REFLEXÕES SOBRE O CARÁTER NORMATIVO DO DIREITO INTERNACIONAL E SOBRE O PAPEL DA SOBERANIA}

Justiça decidiu que houve "violação, pela ação da marinha de guerra britânica, da soberania da Albânia" (CORTE INTERNACIONAL DE JUSTIÇA, 1949, p. 35). Esta é uma sentença, embora nenhuma medida de execução tenha sido necessária. No caso relativo aos Direitos dos Nacionais dos Estados Unidos da América no Marrocos, a Corte Internacional de Justiça (1952, p. 213) decidiu que os nacionais norte-americanos não eram isentos de certos impostos. Esta era igualmente uma decisão definitiva que não pedia nenhuma medida de execução, apenas uma aquiescência. Tal situação pode igualmente ser verificada na decisão da Corte no caso do Camarões Setentrional. Neste caso, apesar de definitiva, a sentença não requeria nenhuma medida de execução (CORTE INTERNACIONẢL DE JUSTIÇA, 1963, p. 38). A matéria veio inclusive a ser tratada pelo Juiz P. C. Jessup, que no caso do Sudoeste Africano de 1962 já havia salientado que:

[S]e considerarmos que o artigo 60 [do Estatuto da CIJ, que trata da natureza definitiva da sentença], e o artigo 94, b, 1 [da Carta das Nações Unidas, que trata da execução das sentenças] não se aplicam senão às sentenças apelando para a adoção de uma medida positiva, o alcance desses artigos seria muito diminuído. (CORTE INTERNACIONAL DE JUSTIÇA, 1966, p. 337)

Conclui-se, assim, que os argumentos que visam desqualificar a natureza normativa do direito internacional, não encontram acolhimento no universo jurídico. A ordem normativa internacional funciona como um instrumento gerador de regras previsíveis que permitem estabilizar as relações entre os diversos sujeitos de direito internacional (RUZIÉ, 2008, p. 01). Sua força normativa não necessita de prova material, bastando a demonstração de que o direito internacional é de fato considerado e reconhecido como direito pelos seus autores e destinatários (PELLET; DAILLIER, 2009, p. 100-104).

\section{A SOBERANIA COMO ELEMENTO DISTINTIVO DA ORDEM NORMATIVA INTERNACIONAL}

Partindo desta constatação, uma nova questão se coloca. O fato de reconhecer a natureza normativa do direito internacional não significa compreendê-lo em sua totalidade. Esta percepção decorre do real 


\section{REVISTA ESTUDOS INSTITUCIONAIS}

entendimento do seu elemento distintivo, ou seja, daquilo que o caracteriza na sua essência. Em outras palavras, a soberania (PELLET; DAILLIER, 2009, p. 95). O direito internacional é, por natureza, um atributo da soberania, assim, a capacidade soberana figura como o elemento indicativo primordial da autoridade da norma.

Embora a realidade jurídica internacional e interna seja distinta, o Estado ainda figura como o denominador comum e o principal agente no âmbito dessas duas ordens normativas (BROWNLIE, 1997, p. 72; ÇALI, 2010, p. 191). Evidentemente, tal afirmação não visa a excluir toda a importância da inclusão do indivíduo na esfera internacional ou a necessária garantia de direitos fundamentais próprias ao direito interno. Contudo, é inegável que nos dias de hoje os sistemas normativos interno e internacional, apesar de constituídos de forma autônoma, se relacionam prioritariamente, direta ou indiretamente com a figura estatal (FRIEDMAN, 1964, p. 213). ${ }^{11}$ Assim, mesmo que se possa sustentar a ideia de que o indivíduo é o destinatário final e absoluto da norma, seja ela interna ou internacional, o Estado ainda é, simultaneamente, o ente predominante deste processo e o elemento de interseção entre estas duas esferas normativas. ${ }^{12}$

Tal constatação conduz a uma questão preliminar. Se o Estado é o ente principal nos dois sistemas sociais é obvio que aquilo que representa o seu valor intrínseco e essencial, seu núcleo duro e seu fundamento devem estar na base originária de sua existência e de seu comportamento. Este elemento inerente à figura estatal está, portanto, na gênese da lógica normativa que dele decorre, seja ela interna ou internacional e deve, assim, moldar as suas especificidades e características. Mas que componente é este? Qual seria, finalmente, o elemento constitutivo e essencial do Estado impresso na ordem normativa?

É certo que a constituição de um Estado é normalmente estabelecida a partir da presença de um território determinado e de uma população representada por um conjunto de pessoas. Tais elementos são mencionados no artigo $1^{\circ}$ da Convenção de Montevidéu sobre os Direitos e Deveres dos Estados de 1933, o qual é considerado como um ponto de partida para a definição do Estado como sujeito de direito internacional.

11 Nesse sentido, Aust (2005, p. 16) afirma que “as organizações internacionais, as organizações não governamentais e os indivíduos ainda exercem apenas papel coadjuvante [na ordem internacional]" e que "apenas os Estados possuem personalidade jurídica na extensão máxima".

12 Anand (1986, p. 28) explica que a soberania de cada Estado impõe deveres mútuos de se abster e de não interferir em partes de outros sujeitos de direito internacional. Dessa forma, a soberania e a jurisdição doméstica apresentam-se como termos intercambiáveis. Cf. Jessup (1948, p. 17). 


\section{REFLEXÕES SOBRE O CARÁTER NORMATIVO DO DIREITO INTERNACIONAL E SOBRE O PAPEL DA SOBERANIA}

Ademais, nos incisos III e IV, o artigo $1^{o}$ elenca ainda os requisitos que um Estado deva apresentar para ser considerado como pessoa de direito internacional, ou seja, a existência de um governo e a capacidade de entrar em relações com os demais Estados (BRASIL, 1937).

Isso significa que para que se obtenha a concepção de Estado é necessário que esta população e este território estejam sob a tutela de uma forma específica de poder político independente que, por sua própria natureza, excluiria qualquer outro. ${ }^{13} \mathrm{Em}$ outras palavras, o território e a população representam condições indispensáveis para que a autoridade política se exerça de forma eficaz. É esta capacidade de comando que simboliza a essência do Estado (PELLET; DAILLIER, 2009, p. 450 e 458464), a qual se dá o nome de soberania. Soberania e Estado são, portanto, conceitos que, desde o século XVII, com a consolidação dos acordos de Westfália de $1648^{14}$, caminham irmanados, um não existindo sem o outro (MELLO, 1999, p. 07). O Estado encontra resguardo, justificativa, autoridade e legitimidade na noção de soberania, ao passo que esta figura como um atributo essencial do Estado (CANAL-FORGUES; RAMBAUD, 2011, p. 181; ÇALI, 2010, p. 193; SINKONDO, 1999, p. 270).

Com efeito, esse vínculo inerente tem uma profunda consequência para o direito internacional. Se a soberania é o elemento essencial do Estado, e este é o principal ente internacional, o direito internacional deve ser visto como a concepção jurídica da noção de soberania, seu reflexo e sua representação normativa. ${ }^{15}$ Neste sentido, o direito internacional se adapta acompanhando o dinamismo mutante da percepção e da atuação da soberania na esfera internacional.

\footnotetext{
${ }^{13}$ No mesmo sentido, no caso da Ilha das Palmas, o Árbitro Max Huber afirmou que a “[s]oberania nas relações entre os Estados significa independência. A independência em relação a uma porção do globo é o direito de exercer nesta, excluindo-se a atuação de qualquer outro Estado - as funções de um Estado. O desenvolvimento da organização nacional dos Estados nos últimos séculos, e, como consequência, o desenvolvimento do direito internacional, estabeleceram o princípio da competência exclusiva do Estado em relação ao seu próprio território de tal forma que ele foi usado como ponto de partida para solucionar grande parte das questões concernentes às relações internacionais" (CORTE PERMANENTE DE ARBITRAGEM, 1928, p. 838).

${ }^{14}$ Os acordos de Münster e Osnabrück marcaram o fim da Guerra dos Trinta Anos. A partir de então a "soberania incluía autoridade total e exclusiva sobre o território em questão". "Westfália codificou a doutrina no sistema europeu estatal segundo a qual nenhuma entidade, imperador, papa ou outro tomador de decisões, estaria acima do nível do Estado" (ÇALI, 2010, p. 193-194).

$15 \mathrm{O}$ vínculo entre Estado, soberania e direito internacional vem sendo tradicionalmente demonstrado pela doutrina. Como sustenta Korowicz (1961, p. 16): "não há direito internacional sem Estados soberanos que o criem; a existência do direito internacional depende da vontade dos Estados que o criaram, e podem, igualmente, revogá-lo".
} 


\section{REVISTA ESTUDOS INSTITUCIONAIS}

\section{A concepção jurídica da noção de soberania e sua aplicação na esfera internacional}

É certo que a soberania pode ter acepções das mais variáveis. Ela pode ser observada em sua dimensão econômica, política, ideológica, social, ambiental ou mesmo cultural. Sem, contudo, desqualificar nenhuma destas eventuais perspectivas pretende-se aqui enfatizá-la à luz da constituição do Estado e de seu papel determinante na formação do direito internacional (ROSSEAU, 1974, p. 309). Nesta dimensão, observase que a soberania atua dentro de uma dupla perspectiva, a primeira de ordem positiva e a segunda, negativa.

A concepção positiva da soberania decorre do princípio elementar da igualdade entre os Estados (BROWNLIE, 1997, p. 309), expresso no artigo 2º, alínea 1 da Carta das Nações Unidas (BRASIL, 1945), bem como da Declaração de Princípios Relativos às Relações de Amizade e Cooperação entre os Estados, que sublinhou que todos os Estados gozam de igualdade soberana entre si e, como membros equânimes da comunidade internacional, são iguais em direitos e deveres, não obstante as suas diferenças econômicas, sociais, políticas ou de outra natureza (ASSEMBLEIA GERAL DAS NAÇÕES UNIDAS, 1970).

Tal conceito reflete a inexistência de um poder normativo superior ao do autor do ato. Neste sentido, a soberania sob a ótica da esfera internacional não designa os poderes do Estado para com seus nacionais, pois esta não está ambientada em uma relação vertical entre o Estado e aqueles que dele fazem parte, mas sim em uma relação horizontal entre iguais. Isso significa, basicamente, que apesar das diferenças de natureza econômica, social, política ou de qualquer outro gênero, os Estados, exatamente por serem soberanos e juridicamente iguais, podem produzir direito internacional e destinar a norma a eles próprios. ${ }^{16}$ Portanto, à luz do direito internacional, a igualdade entre os membros da sociedade internacional significa que a soberania deve ser entendida como a capacidade de se relacionar entre pares. Ela é, assim, o elemento que permite conferir a uma norma o seu selo jurídico, a sua autoridade e a sua

\footnotetext{
16 Tal realidade não obscurece o contraponto sublinhado por Virally (1983, p. 78), que salienta que para além do reconhecimento da igualdade soberana se instala uma poderosa luta política. A desigualdade e a diversidade real de meios e de situações provocam uma tentativa constante de se evitar a reciprocidade ou reverter às consequências negativas desta pretensa igualdade. Naturalmente os Estados recorrem à soberania para justificar a existência de direitos e pretensões que lhe seriam úteis negando a existência de obrigações consideradas inconvenientes.
} 


\section{REFLEXÕES SOBRE O CARÁTER NORMATIVO DO DIREITO INTERNACIONAL E SOBRE O PAPEL DA SOBERANIA}

legitimidade (CANAL-FORGUES; RAMBAUD, 2011, p. 181; PELLET; DAILLIER, 2009, p. 99).

Partindo desta concepção, o direito internacional não deve ser visto como uma limitação da soberania, mas ao contrário, como o seu próprio exercício positivado. É a soberania o elemento que finalmente legitima e autoriza a produção da norma na esfera internacional. O direito internacional é um predicado da soberania, e não a sua renúncia. Este não é imposto, mas desejado e produzido a partir de uma capacidade que a soberania delega. A soberania e o direito que dela decorre correspondem, assim, ao cimento que consolida a existência de um Estado e seu modo de atuação junto aos seus pares e aos outros sujeitos de direito internacional.

Sob este prisma, a soberania é perfeitamente compatível com o exercício do direito. A Corte Permanente de Justiça Internacional, em sua célebre decisão no caso do S.S. Wimbledom, esclareceu que:

Toda Convenção provoca uma restrição ao exercício de direitos soberanos de um Estado, no sentido em que ela imprime a este exercício uma direção determinada. Mas a faculdade de realizar engajamentos internacionais é precisamente um atributo da soberania do Estado

(CORTE PERMANENTE DE JUSTIÇA

INTERNACIONAL, 1923, p. 25).

E a Corte Internacional de Justiça complementa a matéria no caso das Atividades Militares e Paramilitares na Nicarágua salientando que: "o Estado (...) é soberano para aceitar (...) uma limitação a sua soberania" (CORTE INTERNACIONAL DE JUSTIÇA, 1986, p. 131). Deste modo, o Estado pode livremente, em função da conveniência de seus interesses e sem ingerência estrangeira (ASSSEMBLEIA GERAL DAS NAÇÕES UNIDAS, 1975), produzir direito como manifestação soberana. Ele goza de liberdade de ação sem a necessidade de autorização ou habilitação especial para agir na esfera internacional (CANAL-FORGUES; RAMBAUD, 2011, p. 183).

Em outros termos, a soberania positiva refletida no princípio da igualdade está representada no poder do Estado de regular livremente por via normativa os seus próprios interesses ${ }^{17}$, sem sujeição a qualquer

17 V. Lowe (2007, p. 116) aponta ainda o princípio da igualdade soberana entre os Estados pode ser observado nas presunções de direito igualitário de voto no seio das 


\section{REVISTA ESTUDOS INSTITUCIONAIS}

JULHO/DEZEMBRO - ISSN 2447-5467

entidade superior: summa potestas superiorem non recognoscens (PELLET; DAILLIER, 2009, p. 95 e 450). Ela permite que os Estados se situem em uma posição de igualdade jurídica, ainda que por um lado, em certas circunstâncias, como no caso do Saara Ocidental, este princípio pareça excessivamente formal e irreal ${ }^{18}$, e por outro a soberania não autoriza os Estados a atuar com liberdade ilimitada na esfera internacional, de forma que estes devem respeitar "as exigências elementares da paz, da segurança e da cooperação internacional, assim como aquelas relativas à proteção internacional dos direitos humanos" (SINKONDO, 1999, p. 270).

A clássica definição de soberania é aquela formulada pelo suíço Max Huber em sua decisão arbitral relativa à Ilha de Palmas que opunha os Estados Unidos aos Países Baixos. Em seu laudo arbitral, datado de abril de 1928, Huber concluiu que a "soberania nas relações entre os Estados significa independência. [E que esta] deve ser entendida como o direito de exercer as funções soberanas estatais, com exclusão de qualquer outro Estado" (CORTE PERMANENTE DE ARBITRAGEM, 1928, p. 838). Observa-se aqui o conceito de soberania na sua vertente negativa. A soberania representa tanto a independência relativa à norma produzida por outro ente soberano, quanto a limitação do exercício normativo de uma entidade soberana vis-à-vis de outra. Esta é igualmente a definição dada pelo Dictionnaire de droit international que tratou a soberania como uma característica inerente ao Estado representada pela não submissão a nenhum outro poder de mesma natureza (SALMON, 2001).

Neste caso a soberania é particularmente limitativa, pois significa o não condicionamento de um determinado Estado ao poder normativo de outro. Ela está impressa no fato de que o ente soberano não deve estar submetido à autoridade de um terceiro. Ser soberano significa desconhecer qualquer servilismo normativo. Neste caso, a ordem internacional deve ser vista como composta por uma pluralidade de Estados protegidos juridicamente pela contenção da soberania alheia. Mesmo Grotius (1999, p. 2898) no século XVII já definia a soberania como

organizações internacionais e de igual aplicabilidade das normas internacionais a todos os Estados.

18 No parecer consultivo relativo ao caso do Saara Ocidental, a Corte Internacional de Justiça (1975, p. 37-40) afirmou que, à época da colonização espanhola, o Saara Ocidental não era uma terra nullius. Sendo assim, a aquisição de soberania não ocorreu por meio de uma ocupação (originalmente definida como meios pacíficos de adquirir soberania sobre uma terra nullius), mas sim por meio de acordos realizados com os líderes do território, o que configurou uma cessão. Nesse sentido, a legitimidade de tais acordos foi verificada em função da soberania daquela nação, uma vez que se tratava de um território habitado por tribos e indivíduos agrupados em uma organização política e social. 


\section{REFLEXÕES SOBRE O CARÁTER NORMATIVO DO DIREITO INTERNACIONAL E SOBRE O PAPEL DA SOBERANIA}

a capacidade de produzir atos não dependentes de maneira a não serem anulados por vontade estrangeira. Nesta mesma linha E. Vattel a identificava com a independência, e a definia como a capacidade de se autogovernar por intermédio de sua própria autoridade e de suas próprias leis. ${ }^{19} \mathrm{O}$ artigo 3, alínea b, da Carta da Organização dos Estados Americanos regulamenta a mesma ideia e, em uma visão contemporânea, estabelece que "a ordem internacional é constituída essencialmente pelo respeito à personalidade, soberania e independência dos Estados" (BRASIL, 1952).

Identificar soberania e independência do Estado na relação com seus pares autoriza automaticamente o reconhecimento de outras prerrogativas, tais como o direito à não intervenção em seus assuntos internos, o direito à integridade territorial, o direito à imunidade jurisdicional, entre outros. Ser soberano, significado, portanto, ser independente e não estar submetido, de forma colonial ou qualquer outro modo de domínio, a uma vontade ou a um império alheio (PELLET; DAILLIER, 2009, p. 95 e 467). Sendo assim, a independência reflete um modelo de soberania negativa representada no universo do direito internacional como a capacidade de não se sujeitar a nenhuma produção normativa realizada por outra entidade soberana sem que seja manifestado, de um modo ou de outro, algum modelo de consentimento ou aceitação.

\section{CONCLUSÃO}

O direito internacional se caracteriza como uma ordem normativa, possuindo regras agrupadas de forma sistemática e coerente. Apesar de ainda existirem críticas a tal constatação, vindas especialmente daqueles que baseiam sua concepção de ordem jurídica no modelo do direito interno, é inegável que o direito internacional possui características comuns a todas as ordens normativas.

Mesmo sem possuir uma estrutura complexa para sua criação e execução, as normas do direito internacional visam regular a conduta dos Estados e outros atores internacionais, criando obrigações para tais entes. É verdade que em algumas ocasiões tais obrigações não são cumpridas justamente pela inexistência de um órgão executor de grande poder, mas

19 Toda Nação que se governa por si mesma, sob qualquer forma que seja, sem dependência de nenhum estrangeiro, é um Estado soberano. Os seus direitos são naturalmente os mesmos dos demais Estados (VATTEL, 2004, p. 16). 


\section{REVISTA ESTUDOS INSTITUCIONAIS}

tal fato não quer dizer que as normas do direito internacional não existem, pois, o mecanismo de coerção se vincula à eficácia, e não à existência da norma. Eventuais episódios em que normas do direito internacional são violadas não nos levam à conclusão de sua inexistência, ao contrário, comprovam que uma norma existente foi ofendida. Ademais, tal como no direito interno, algumas normas do direito internacional não necessitam da coerção para serem executáveis, como as normas declaratórias. A frase de J. de Louter de que "o direito internacional é um direito sem legislador, sem gendarme e sem juiz" (LOUTER, 1920) reafirma que mesmo não possuindo exatamente as mesmas características que o direito interno, o direito internacional não deixa de ser direito.

Como visto, as particularidades do direito internacional derivam do conceito de soberania, elemento que o distingue de todos os outros ramos do direito. A soberania, cuja correlação com o próprio conceito de Estado existe desde o início da Era Moderna, tem no direito internacional sua representação no mundo jurídico e a ele atribui sua legitimidade. O poder legiferante do direito internacional está, portanto, nos próprios Estados que compõem a comunidade internacional.

Le droit international c'est un droit sans législateur, sans gendarme et sans judge (LOUTER, 1920). A frase de J. de Louter, por vezes utilizada pelos críticos do direito internacional para negar-lhe o caráter de sistema normativo, contraditoriamente reafirma sua conceituação como direito.

$\mathrm{O}$ direito internacional pode não ter legislador, gendarme e juiz tal como o direito interno. Mas isto, conforme preconiza a própria frase de Louter, não o faz deixar de ser direito.

\section{REFERÊNCIAS}

ABI-SAAB, G. General Course in Public International Law. Recueil des Cours de l'Académie de Droit International de la Haye (RCADI), Haia, v. 207, 1987.

ALLOTT, Philip. The Concept of International Law. European Journal of International Law, vol. 10, p. 31-50, 1999.

ANAND, R. P. Sovereign Equality of States in International Law. Recueil des Cours de l'Académie de Droit International de la Haye (RCADI), Haia, v. 197, 1986. 
ARENDT, Hannah. Entre o Passado e o Futuro. São Paulo: Perspectiva, 1992.

ASSEMBLEIA GERAL DAS NAÇÕES UNIDAS. Declaration on Principles of International Law concerning Friendly Relations and Cooperation among States in accordance with the Charter of the United Nations. UNGA Res. 2625 (XXV), 24 de outubro de 1970.

ASSEMBLEIA GERAL DAS NAÇÕES UNIDAS. Declaration on the Use of Scientific and Technological Progress in the Interests of Peace and for the Benefit of Mankind. UNGA Res. 3384 (XXX), 10 de novembro de 1975.

AUST, Anthony. Handbook of International Law. Cambridge: Cambridge University Press, 2005.

BEDJAOUI, Mohammed. Droit International: Bilan et perspectives. Paris: Éditions Pedone, 1991.

BISHOP, William. General Course in Public International Law. Recueil des Cours de 1'Académie de Droit International de la Haye (RCADI), Haia, v. 115, 1965.

BRANT, Leonardo Nemer Caldeira. Fundamentos da Existência e Validade do Direito Internacional. Revista da Faculdade de Direito da UFMG, n. 62, p. 367-375, 2013.

BRASIL. Decreto no 1.570 , de 13 de abril de 1937. Promulga as Convenções sobre direitos e deveres dos Estados e sobre Asilo político, assinadas em Montevidéo a 26 de dezembro de 1933, por ocasião da Sétima Conferencia internacional americana. 1937. Disponível em: < http://www.planalto.gov.br/ccivil_03/decreto/1930-1949/d1570.htm>. Acesso em: 14 dez. 2018. 


\section{REVISTA ESTUDOS INSTITUCIONAIS}

BRASIL. Decreto no 19.841, de 22 de outubro de 1945. Promulga a Carta das Nações Unidas, da qual faz parte integrante o anexo Estatuto da Corte Internacional de Justiça, assinada em São Francisco, a 26 de junho de 1945, por ocasião da Conferência de Organização Internacional das Nações Unidas. 1945. Disponível em: < http://www.planalto.gov.br/ccivil_03/decreto/1930-1949/D19841.htm>. Acesso em: 14 dez. de 2018.

BRASIL. Decreto oㅜ 30.544, de 14 de fevereiro de 1952. Promulga a Carta da Organização dos Estados Americanos, firmada em Bogotá, a 30 de abril de 1948. 1952. Disponível em: <

http://www2.camara.leg.br/legin/fed/decret/1950-1959/decreto-30544-14fevereiro-1952-340000-publicacaooriginal-1-pe.html>. Acesso em: 14 de dez. de 2018.

BROTÓNS, Remiro. Derecho Internacional. Valência: Tirant lo Blanch, 2007.

BROWNLIE, Ian. International law at the fiftieth anniversary of the United Nations: General Course on Public International Law. Recueil des Cours de l'Académie de Droit International de la Haye (RCADI), Haia, v. 255, 1995.

BROWNLIE, Ian. Princípios de Direito Internacional Público. Lisboa: Fundação Calouste Gulbenkian, 1997.

BUERGENTHAL, Thomas; MURPHY, Sean. Public International Law in a Nutshell. St. Paul: Westgroup, 2003.

ÇALI, B. International Law for International Relations. Oxford: Oxford University Press, 2010. 
CAMPOS, J. D. G. Curso de Derecho Internacional Publico. Madri: Civitas, 1998.

CANAL-FORGUES, E.; RAMBAUD, P. Droit International Public. Paris: Flammarion, 2011.

COMBACAU, Jean. Le droit international: bric-à-brac ou système? Archives de Philosophie du Droit, Paris, v. 31, p. 85-105, 1986.

CORTE INTERNACIONAL DE JUSTIÇA. Atividades Militares e Paramilitares na Nicarágua (Nicarágua v. Estados Unidos). CIJ Rec. 1986.

CORTE INTERNACIONAL DE JUSTIÇA. Camarões Setentrional (Camarões v. Reino Unido). CIJ Rec. 1963.

CORTE INTERNACIONAL DE JUSTIÇA. Direitos dos Nacionais dos Estados Unidos da América no Marrocos (França v. Estados Unidos). CIJ Rec. 1952.

CORTE INTERNACIONAL DE JUSTIÇA. Estreito de Corfu (Reino Unido v. Albânia). CIJ Rec. 1949.

CORTE INTERNACIONAL DE JUSTIÇA. Saara Ocidental (Opinião Consultiva). CIJ Rec. 1975.

CORTE INTERNACIONAL DE JUSTIÇA. Sudoeste Africano (Libéria v. África do Sul). Opinião Dissidente do Juiz Jessup. CIJ Rec. 1966.

CORTE PERMANENTE DE ARBITRAGEM. Ilha de Palmas (Países Baixos v. Estados Unidos da América). Reports of International Arbitral Awards, vol. II. P. 829-871, 1928. 


\section{REVISTA ESTUDOS INSTITUCIONAIS}

CORTE PERMANENTE DE JUSTIÇA INTERNACIONAL. S.S. Wimbledon (França v. Alemanha). CPJI Série A, nº 1, 1923.

DE BÉCHILLON, D. Qu'est-ce qu'une Règle de Droit? Paris: Ed. Odile Jacob, 1997.

DUPUY, Pierre-Marie. Droit International Public. Paris: Éditions Dalloz, 2006.

FINNEMORE, Martha. Are Legal Norms Distinctive? New York University Journal of International Law and Politics, Nova York, v. 32, p. 699-705, 1999-2000.

FRIEDMAN, W. The Changing Structure of International Law. Nova York: Columbia University Press, 1964.

GOODRICH, L.; HAMBRO, E. Charter of United Nations. Nova York: Columbia University Press, 1969.

GROTIUS, Hugo. De Jure Belli Ac Pacis. Livro 1. Paris: PUF, 1999.

GUGGENHEIM, Paul. Traité de Droit International Public. $1^{1}$ ed, Tomo I. Genebra: Librarie de L’Université, 1967.

HART, H. L. A. The Concept of Law. Oxford: Oxford University Press, 1994.

JESSUP, Philip C. A Modern Law of Nations. Nova York: Macmillan, 1948.

KELSEN, Hans. Teoria Pura do Direito. São Paulo: Martins Fontes, 1962. 
KERLEY, E. L. Ensuring Compliance with Judgments of the International Courts of Justice. In: GROSS, L. (Org.). The Future of the International Court of Justice. Vol.1. Nova York: Dobbs Ferry, 1976.

KOLB, Robert. Théorie du droit international. $2^{\mathrm{a}}$ ed. Bruxelas: Bruyant, 2013.

KOROWICZ, Marek Stanislaw. Some Present Aspects of Sovereignty in International Law. Recueil des Cours de l'Académie de Droit International de la Haye (RCADI), Haia, v. 102, 1961.

KRATOCHWIL, F. V. The puzzles of politics: inquiries into the genesis and transformation of international relations. Abingdon: Routledge, 2010.

LOUTER, Jan de. Le droit international public positif. Tomo I. Oxford: Imprimerie de l'Université, 1920.

LOWE, V. International Law. Oxford: Oxford University Press, 2007.

MELLO, Celso D. A Soberania Através da História. In ARNAUD, André Jean (Org.). Anuário Direito e Globalização. Rio de Janeiro: Renovar, 1999.

O'BRIEN, John. International Law. Londres: Cavendish Publishing Limited, 2001.

PELLET, Alain. The Normative Dilemma: Will and Consent in International Law-making. Australian Year Book of International Law, Camberra, v. 12, p. 22-53, 1992.

PELLET, Alain; DAILLIER, Patrick. Droit International Public. Paris: LGDJ L'Extenso Éditios, 2009. 


\section{REVISTA ESTUDOS INSTITUCIONAIS}

PEREIRA, Bruno Yepes. Curso de Direito Internacional Público. São Paulo: Saraiva, 2006.

REALE, Miguel. Lições Preliminares de Direito. São Paulo: Saraiva, 2004.

REISMAN, W. M. Nullity and Revision, Review and Enforcement of International Judgements and Awards. New Heaven: Yale University Press, 1971.

ROSENNE, S. Law and Practice of International Court. Haia: Martinus Nijhoff, 1997.

ROUSSEAU, Charles. Droit International Public. Paris: Sirey, 1974.

RUGGIE, J. G. Constructing the World Polity: Essays on International Institutionalisation. Abingdon: Routledge, 1998.

RUZIÉ, D. Droit International Public. Paris: Dalloz, 2008.

SALMON, Jean. Dictionnaire de Droit International. Bruxelas: Bruylant, 2001.

VIRALLY, O. The Enforcement of International Judicial and Arbitral Decisions. American Journal of International Law, Nova York, n.1, v. 54, p. 1-24, 1960.

SCOBBIE, Ian; EVANS, M. Some common heresies about international law: sundry theoretical perspectives. In EVANS, M. D. (Org.). International Law. Oxford: Oxford University Press, 2003. P. 59-87.

SHAW, Malcolm. International Law. Cambridge: Cambridge University Press, 2003. 
SINKONDO, M. Droit International Public. Paris: Ellipses, 1999.

STRUPP, K. Règles Générales du Droit de la Paix. Recueil des Cours de 1'Académie de Droit International de la Haye (RCADI), Haia, v. 47, 1934.

VATTEL, Emmerich de. O Direito das Gentes. Brasília: Editora Universidade de Brasília / IPRI, 2004.

VIRALLY, Michel. Notes sur la validité du droit et son fondament (norme fondamentale hypothétique et droit international). In WALINE, Marcel (Org.). Recueil d'études en hommages à Charles Eisenmann. Paris: Éditions Cujas, 1975.

VIRALLY, Michel. Panorama du Droit International Contemporain. Recueil des Cours de l'Académie de Droit International de la Haye (RCADI), Haia, v. 183, 1983.

VIRALLY, Michel. Sur la prétendue « primitivité » du droit international. In VIRALLY, Michel. Le droit international en devenir: Essais écrits au fil des ans. Genebra: Librairie de l'Université Georg \& Cia, 1969.

WECKEL, P. Les Suites des Décisions de la Cour Internationale de Justice. Annuaire français de droit international, Paris, n. 1, v. 42, p. 428-442, 1996.

RECEBIDO EM: 23/10/2017.

ACEITO EM: 30/04/2018. 